\title{
Effects of Interactive Real-Time Simulations and Humanoid Avatars on Consumers' Responses in Online House Products Marketing
}

\author{
Lamine Mahdjoubi* \\ Faculty of Environment and Technology, Department of Construction and Property, Frenchay Campus, Coldharbour \\ Lane, University of the West of England, Bristol BS16 1QY, United Kingdom \\ Jing Hao Koh \\ School of Architecture, Building \& Design, Taylor's University, Lakeside Campus, No. 1, Jalan Taylor's, 47500 Subang \\ Jaya, Selangor, Malaysia \\ $\&$ \\ Cletus Moobela \\ School of Civil Engineering and Surveying, The University of Portsmouth, Portland Building, Portsmouth PO1 3AH, \\ United Kingdom
}

\begin{abstract}
Interactive product presentation techniques have recently gained importance in online marketing of house products. Real-time simulation offers a high level interactive presentation with more powerful features to present product functions and variations. This article presents a novel computational approach for engaging and supporting consumers in making informed choices about purchasing house products. It involved the development and testing of an online interactive real-time simulation for house product marketing (the Virtual House Showroom-VHS). This model also included optional humanoid avatars, representing a virtual buyer-seller experience. The research assessed the effectiveness of the VHS on consumers' cognitive and affective responses. In particular, it examined whether consumers' responses to real-time simulation with a humanoid avatar are significantly different from their responses to the model without the avatar. Participants $(n=110)$ were organized into two groups. Group 1 $(n=56)$ evaluated VHS without the humanoid avatar and group $2(n=54)$ appraised the model with the

\footnotetext{
*To whom correspondence should be addressed. E-mail: lamine. mahdjoubi@uwe.ac.uk.
}

avatar. The results confirmed that interactive online realtime simulation technologies without the avatar have significant effects on consumers' cognitive learning, affect, and behavior. However, it was found that the humanoid avatar had no significant effect on respondents' decision-making. Further research was suggested to improve the usability of real-time simulation in the marketing of house products.

\section{INTRODUCTION}

Interactive product presentation techniques are gaining increasing prominence in online marketing of house products. This may be attributed to two key factors. Firstly, there are numerous limitations associated with the conventional methods. Secondly, advances in computer simulations have enabled the emergence of product presentation techniques in the form of interactive real-time simulations. Virtual Reality (VR) or real-time simulation is a technology that enables users to experience a computer generated environment and interaction with virtual objects in real-time (Yee et al., 2007). VR has been tested extensively in various Architecture, 
Engineering and Construction (AEC) applications, including education. For instance, Dossick et al. (2010) sought to bring the excitement, attractiveness, and impact of videogame-like environments to educational settings. They explored educational computer simulations to provide user experiences that allow for immersion into a dynamic system in which participants discover the ramifications of their decisions in a complex environment. Adeli and Kim (2000) developed a web-based approach and courseware to complement the teaching of structural steel design to allow an improved interaction between instructors and their students. Other research sought to build three-dimensional (3D) models of buildings and terrains for representing, managing, and documenting building activity and maintenance work (Zalama et al., 2011). More recently, advanced scan planning methodology was developed for obtaining accurate 3D virtual models from real buildings (Kuldeep et al., 2012).

Based on technologies developed for the World Wide Web, Fu and East (1999) proposed the Virtual Design Review to enable a group of reviewers to work in realtime on a 3D representation of an incomplete building model. Within this model, each client is represented by an avatar that can move about the Virtual Reality Modeling Language (VRML) building model and interact with other clients' avatars. These efforts paved the way for the generation of high level, interactive, online, realtime simulations with more powerful features to represent product functions and variations.

In this article, a novel computational approach for engaging and supporting consumers in making informed choices about purchasing house products is presented. This approach required the development and testing of an online interactive real-time simulation for house product marketing (the Virtual House ShowroomVHS).

\section{MARKETING METHODS AND TECHNIQUES IN AEC}

The Chartered Institute of Marketing (CIM, 2008) defines marketing as the management process responsible for identifying, anticipating, and satisfying customers' requirements profitably. Current marketing methods and techniques adopted by AEC companies can be categorized into online and offline marketing methods. The latter are those used to promote AEC products and services in a conventional way. These may include brochures, magazines, catalogues, newspaper advertisements, radio or television advertising, direct mail, and showrooms. The online marketing methods and techniques on the other hand utilize the Internet as a platform for showcasing and promoting AEC prod- ucts and services. Both marketing methods and techniques have their respective strengths and limitations (Zaleon, 2007).

Print materials (brochures, catalogs, magazines, and newspaper advertisements) might be effective in informing consumers about the latest AEC ranges and styles available and offered by the AEC companies. They are also easily accessible and are capable of presenting an efficient information channel. However, conventional presentation methods have been criticized for their inability to inform consumers about the products' functionalities and variations (Dauner et al., 1998). Consumers may not be able to see how the products function by merely looking at the pictures and text, for example. In addition, the pictures are not sufficient to show the variations in AEC styles and worktop materials. Oh and Hawley (2004) suggested that consumers need additional tools to help them visualize the appearance of furniture units before they can make any purchasing decisions.

The ability of the Internet to present product information effectively has encouraged companies to utilize online advertising as a marketing tool (K.N. Belcher, University of Missouri-Columbia, unpublished results). This is why online shopping or E-commerce is widely used by consumers in recent years as an alternative to traditional shopping. According to Verdict Research (BBC, 2007), there was a $33.4 \%$ increase of spending via online shopping in the UK in 2006. Online marketing and advertising are used as a response to the fast growing online shopping trend (Kiang et al., 2000). AEC companies are using websites as a medium to showcase their products to consumers. Companies are still presenting their products in the form of static visuals with textual descriptions that make the online product presentation no different from the print versions. Yet, developments on the Internet offer the potential for interactivity in product presentation (Stewart and Pavlou, 2002). AEC websites are using various interactive presentation techniques to market their products. Flash animation and $360^{\circ}$ panoramic photo visualization appear to be the popular presentation techniques. However, the interactivity features are limited in terms of demonstrating product functionalities and variations. For example, the Flash animation does not fully demonstrate how an appliance operates. Conversely, $360^{\circ}$ panoramic photo visualization enhances visual realism, but it does not allow movement beyond the viewing point, as well as presenting products' functionalities. Current online AEC interactive presentation is lacking the features that offer virtual product learning and that resembles the real product learning experience.

Another limitation identified in current E-commerce websites is the absence of human contact. The online 
shopping environment is different from the physical stores where sales representatives are present to provide on-the-spot support. This lack of human contact on E-commerce websites directly impacts on consumers' satisfaction and trust levels in the retail environment (Holzwarth et al., 2006; Bauer and Neumann, 2005). The lack of human interaction on AEC websites may lead to the shopping experience being less engaging and motivating. Improved consumers' engagement with the AEC companies' websites has become a crucial issue that needs to be addressed.

\subsection{Potentials of interactive real-time presentations}

Anumba and Ruika (2002) argued that end-users are not necessarily making full use of the E-commerce technology in AEC, and hence do not derive the full benefits from it. Companies are not fully exploiting the growing trend of online shopping, which has increased the usability and potential of online marketing. Online AEC marketing offers consumers a distinct experience from the conventional ones by adding interactivity to product presentations. Stewart and Pavlou (2002) asserted that "the real power of the Internet and the characteristic that differentiates it from traditional media is its potential for interactivity." Interactivity offers AEC companies opportunities to present their products in a format that no conventional media are able to. Research suggests that interactive media have effects on consumers' product learning (Bezjian-Avery et al., 1998). It is suggested that interactive product presentation helps to provide product information in an engaging way. Hence, AEC companies may need to understand how interactivity can improve their online marketing by enhancing consumers' online experience.

The effect of components of interactivity on consumers' behavior in today's commercial environment has attracted a great deal of attention. It was suggested that interactivity is a powerful, yet not well-understood topic in today's media and literature (K.N. Belcher, University of Missouri-Columbia, unpublished results). McMillan and Hwang (2002) postulated a 3D definition of interactivity, embracing: communication direction; user control; and time. Communication direction involves reciprocal communication with responses and feedbacks. User control enables people to manipulate the contents and influence the outcome of their actions in Human-Computer Interaction (HCI). It also involves user interface design and utilities. The perception of web-based interactivity is influenced by the speed at which messages can be delivered and at which people can process messages. This indicates how much time is taken during mutual interaction activities. However, the above definition appears to consist of overlaps between communication direction and time as they happen in the realm of reciprocal communication. Available evidence suggests that consumers' perceptions of the control, responsiveness, and synchronicity of the website have a strong influence on their attitude (Cui et al., 2010).

\subsection{Web-based VR marketing}

Dauner et al. (1998) propose that VR could be used to address the shortcomings of conventional marketing methods to show product functionalities and varieties. Research done by Park et al. (2008) examined the effects of rotation in virtual product presentation on consumers' cognitive, affect, and purchasing intention. Their results showed that consumers perceive a rotating product presentation to provide more product information than a static (non-rotating) product presentation. Similarly, Suh and Lee (2005) found that participants are more likely to remember products shown in real-time simulation than those shown in static media. A study conducted by Lee and Chung (2008) examined consumers' reactions towards a virtual reality shopping mall in comparison to an ordinary shopping environment. Their research showed several important findings, including: that the VR shopping environment creates compelling virtual sensory affluence; consumers are more likely to visit the VR shopping mall again due to enjoyment and convenience; consumers are actively engaged in the VR environment by interacting with virtual objects; and that consumer satisfaction improves, compared to an ordinary shopping environment.

Compared to conventional marketing techniques, VR offers great potential in product presentation. Some companies have already adopted real-time simulation methods to present their products online. As an example, Amica, a Polish electrical appliances company (Amica, 2008), uses VR technology to demonstrate its products online. In this simulation, consumers can test the functionalities of the cooker as if they were examining a real product. Users can open and close the oven door, and cooker knobs can be pulled out and rotated to perform various functions such as timer and temperature controls. These interactive features function as high level stimulation to activate consumers' cognitive learning about the appliance's functionalities and operations. Improved product information helps consumers to make a better evaluation and judgment about the product, which may motivate them to take further purchasing actions.

Personalization plays an important role in interactive product presentation, as it enables consumers to choose products based on their individual tastes and needs (Oh et al., 2004). Personalization enables them to customize the product color and materials to fit their specific requirements. Online car retailers such as 
Toyota often use this technique to let consumers view the available color options for the car. In this Toyota Auris virtual showroom, apart from appearance customizations, users are allowed to rotate the car to view it from different angles. Real-time simulation offers consumers the virtual experience of more than just rotating and customizing vehicle color; consumers can even try out the car by driving it in real-time. These interactive features show the ability of VR to incorporate real-life product demonstration and appearance customizations by using affordable computer technology. Consumers would be attracted to participate and get involved in the product evaluation and this would help them in the purchasing decision-making process. VR technology offers advantages over conventional product presentation media, with immersive environment, interactivity, and personalization features. These features enable users to learn about the product in an engaging and entertaining environment. A recent investigation of the virtual social world "Second Life" (SL) demonstrated that users do not consider SL as a mere computer game, but as an extension of their real lives (Kaplan and Haenlein, 2009). Consequently, marketing managers can use this online application to go beyond those known from traditional computer or online games.

\subsection{Avatars as potential catalysts for human interaction}

Despite the clear potential of VR technology for emarketing, web-based retail is reported to be impersonal and missing the human touch (Holzwarth et al., 2006). Bauer and Neumann (2005) argue that webbased retail is lacking consumer trust. Online consumers often cannot find assistance when facing problems navigating the websites. There are no sales representatives offering assistance or consultations on the spot, as in the physical shopping environment. Prevailing methods adopted by companies to address this issue involve using the Frequently Asked Questions (FAQ) section to answer common queries; but these too lack the power of human interactivity.

Carefully programmed humanoid avatars will be designed to enhance the end-users' visiting experience, and to provide guidance, help, and support by mimicking consumer-seller interaction. Avatars serve at least five distinct communicative functions: regulating conversation flow; providing feedback; communicating emotional information; communicating the nature of interpersonal relationships; and avoiding distraction by restricting visual input (Garau et al., 2001). Emerging trends in real-time simulation have witnessed the use of "virtual humans acting as guides or educators in showroom or e-learning simulations." For example, in the real-time simulation for the scientific theory of explaining the AEC of the Khufu pyramid, architect JeanPierre Houdin was "virtualized" into an avatar as he guides users to explore the mystery of the grand pyramid (Dassault Systèmes, 2007). The simulation takes the users to attend Houdin's lecture in front of their computer. This approach not only engages users, but offers a greater sense of realism, as if the real human is talking to them. Avatars can play an active role in fostering producer-consumer collaboration for product innovation. Kohler et al. (2009) established that avatars could be catalysts for the whole innovation process. Their findings suggest that, to fully realize the potential of avatar-based innovation, companies need to create a compelling open innovation experience and consider the peculiarities of virtual worlds.

To incorporate social presence in the virtual environment, avatars may encourage better users' interaction and involvement with the computer mediated environment. The power of social presence is the ability of participants in a community to project themselves, socially and emotionally, as real people through a medium of communication (Garrison and Anderson, 2003). Avatars are the virtual representation of the human form in cyberspace. They use the basic form of humans to resemble human-human interaction in the virtual world. The reasons for using avatars to depict social presence are that they fulfill the characteristics and factors that determine the extent of perceived social presence. Humans tend to respond better to familiar and similar characteristics than the alternatives. Avatars resemble human characteristics, such as physical form, gestures, kinesthetic movements, emotions, and voice. They can be designed and programmed to look, speak, and behave like real humans. Therefore, users may be easily attracted towards the similarityattraction qualities shown by avatars. Consequently, avatars have the potential to become powerful salespersons. A study by the Virtual Human Interaction Lab, at Stanford University, confirmed that users are more strongly influenced by avatars who mimic their own avatars' body movements and mirror their own appearance. "Using a simple computer script, the selling avatar clerk is able to subtly and automatically tailor its behavior-its gait, the way it turns its head, its facial features-to the avatar buyer's, thus making the clerk seem more friendly, interesting, honest, and persuasive" (Hemp, 2006, p. 50).

Moreover, interacting with other persons has become a part of our life and we understand how people behave according to the social norm. As such, avatars show the consistency-attraction qualities as they perform predictable and consistent behaviors, just like real humans. An experiment by Qiu and Benbasat 
(2005) examined the effects of Text-to-Speech (TTS) and 3D avatars on online consumers' psychology. The results demonstrated that the presence of TTS voice significantly increases consumers' cognitive and emotional trust towards the website's help interface. Hence, with similarity-attraction and consistency-attraction, it is argued that avatars may appeal to consumers. This may contribute to higher levels of perceived virtual experience.

Avatars have the potential to be employed as the company's representation in the virtual world. The effects of using avatars in E-commerce have received a great deal of attention. For example, Holzwarth et al. (2006) examined how avatars on E-commerce websites influence consumers' satisfaction with online retailers. Their study also investigated the extent to which avatars improve consumers' attitudes towards products, as well as their purchasing decisions. Another study was conducted by Bauer and Neumann (2005) to investigate whether avatars build consumer trust towards the retailers. Both studies showed that using avatars on E-commerce websites improves customer satisfaction and trust, as well as positively influencing their behavior. With the similarity-attraction and consistency-attraction factors, avatars offer great potential for making consumers' virtual experience in the sense of experiential marketing.

The development of the VHS model also included the programming of an optional humanoid avatar, called Masha. The humanoid avatar was designed to enhance end-users' virtual visiting experience, and provide guidance, help, and support by mimicking buyer-seller interaction. The research involved the evaluation of the effectiveness of the VHS, with and without the humanoid avatar, on consumers' cognitive, affective, and purchasing decisions.

\section{RESEARCH METHODS}

At the center of the research approach is the theory of Hierarchy of Effects to explain consumers' psychology and behavior. The fundamental concept lies within the three components, cognition, affect, and behavior, which form the framework for understanding consumers' responses (Lavidge and Steiner, 1961). One of the most challenging issues for marketers is how to ensure that consumers obtain, understand, retain, and recall information about products (Mowen and Minor, 1997).

Cognition involves the mental process of understanding, evaluating, planning, deciding, and thinking (Peter and Olson, 2005). Variables such as attention, awareness, comprehension, and learning are related to the cognitive component (Ray, 1973). Consumers receive information, process the information into knowledge, and store it in memory. According to Peter and Olson (2005), consumers' cognitive learning about products can be conceptualized by using the means-end chain model. This model is defined as a simple knowledge structure linking products' attributes to more functional and social consequences, which constitute consumer values.

Affect refers to consumers' affective responses towards a product. This involves emotions, moods, specific feelings, and evaluations (Peter and Olson, 2005). Ray (1973) associated affect with parameters, such as interest, evaluating, attitude, feelings, conviction, and yielding. It is apparent that the main element in consumers' affective responses relates to the emotional aspects. This is different from cognition which involves the mental process. Consumers' affect can be examined in the more specific context of attitude. Foxall and Goldsmith (1998, p. 102) described attitude as "a predisposition to respond in a consistent manner to a stimulus." Attitude reflects the extent to which the product is favorable to consumers, where they show their likes and dislikes when evaluating a product. In terms of marketing implications, understanding consumers' affect and attitude towards a product is critical, as the more positive the consumers' attitude is, the more likely that the product will sell. An experimental study confirmed that both cognitive social presence cues (the provision of information about other consumers online) and affective social presence cues (the use of emotions in online consumer comments) enhance attitude towards a website (Cui et al., 2010).

Consumers' behavior could be perceived as their intentions and actions based on their cognitive learning and attitude towards a product. It may include purchasing intentions, product contact, and actual purchase action. Marketers are interested in knowing the underlying factors that lead to the actual purchase behavior. Fishbein and Ajzen (1975) conceptualized the attitude and behavior relationships in the theory of Reasoned Action. This theoretical framework measures behavior as consequences of beliefs and attitudes. Based on this theory, it is assumed that changing consumers' attitudes may result in a desired behavior.

The research, reported in this article, adopted the theory of Hierarchy of Effects and sought to determine the effects of real-time simulations on house products' marketing. The study sought to answer the following key research questions:

Question 1: Will the real-time simulation enable consumers to make cognitive judgments towards products' features and functions?

Question 2: Is there a significant association between real-time simulations and consumers' affect towards the house products? 


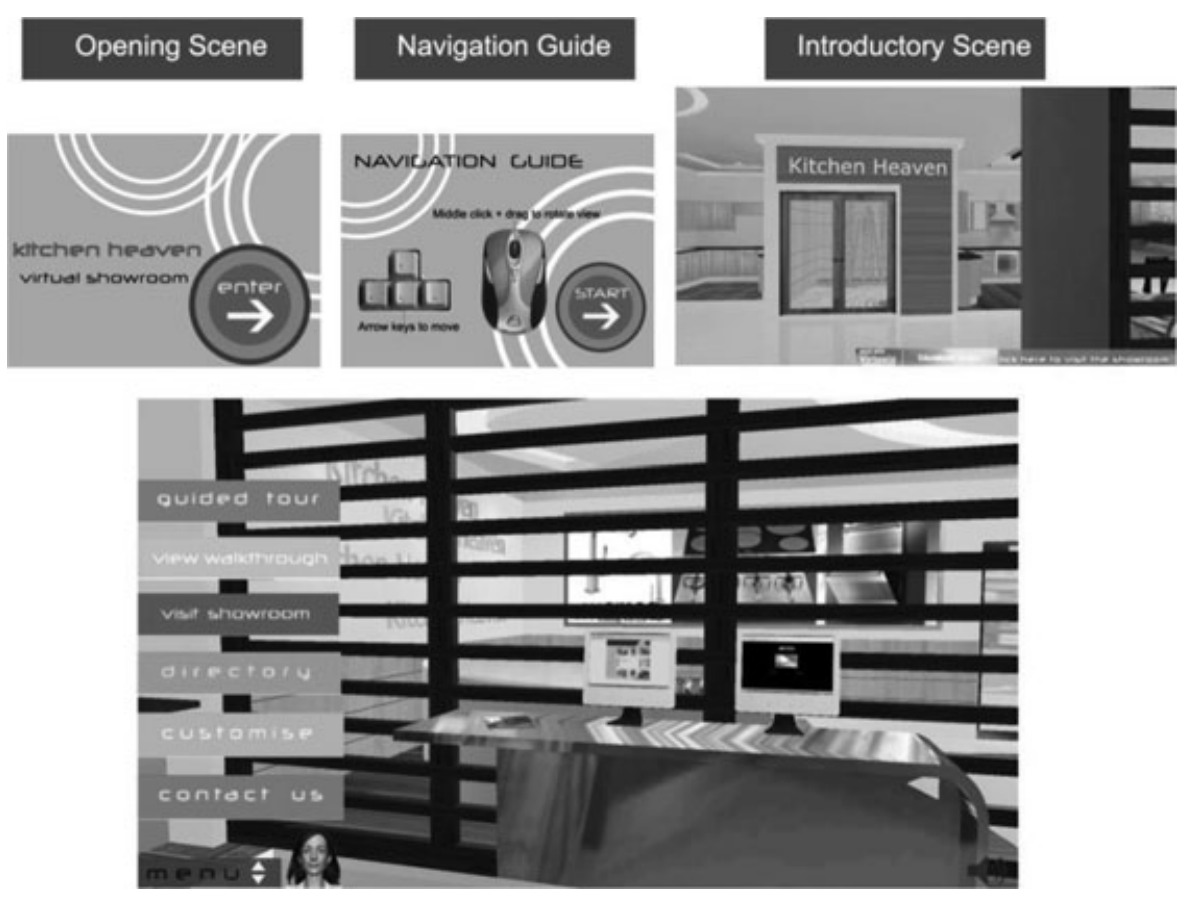

Fig. 1. Real-time simulation interface design.

Question 3: Does real-time simulation significantly influence consumers' purchasing behavior?

Question 4: Will the presence of humanoid avatars in the real-time simulation significantly result in different consumers' responses?

\subsection{Virtual house showroom specification}

The measurement of consumers' responses to VR online marketing involved the development of the VHS that simulated house displays and products. The design of the VHS consisted of an interactive method that visually describes the behaviors of virtual objects, parses the visual scripting, and finally achieves the semantics. The user-friendly interface design ensured smooth operation and avoided confusion. The VHS interface design is illustrated in Figure 1.

\subsection{Interface design}

The opening scene was designed to inform users that the simulation is successfully loaded and that they could begin to experience it at any time. This is indicated by the "Enter" button on the interface. Clicking the button would lead users to the navigation guide scene. This scene was important as it informed them about the navigation methods. Participants could proceed to the next scene by clicking the "Start" button. The next scene was the introductory part with a walkthrough animation and
Table 1

Summary of submenu functions

\begin{tabular}{ll}
\hline Submenu & \multicolumn{1}{c}{ Functions } \\
\hline Guided tour & $\begin{array}{c}\text { Enters the "guided tour" mode where } \\
\text { the avatar provides presentation } \\
\text { about the AEC products' displays } \\
\text { Enters the walkthrough animation } \\
\text { View walkthrough } \\
\text { Visit showroom }\end{array}$ \\
$\begin{array}{l}\text { Eirectory } \\
\text { Customize }\end{array}$ & $\begin{array}{l}\text { Shows the showroom layout } \\
\text { Enters the customization mode which } \\
\text { enables users to change colors }\end{array}$ \\
Contact us & Links to supplier "contact" webpage \\
\hline
\end{tabular}

verbal narrations. The walkthrough animation brought users to look around the showroom to give them an overall impression of what to expect. The verbal narrations described what users could do in the VHS. Users would be prompted to click on the button to enter the "visit showroom" mode where they could freely navigate around by themselves.

A menu button appeared at the bottom of the screen that brought up several submenus. These submenus were critical as they provided an interface to perform various utilities. Users could hide or show the submenus by clicking on the "Menu" button. The virtual showroom was designed with background music, which could be controlled by clicking on the speaker button. The functions of the submenus are summarized in Table 1. 
3.2.1 View walkthrough. In this mode, a camera was assigned to a predefined path around the showroom. Users could not control the movement of the camera and as such could only watch the animation. This walkthrough animation showed the overall environment of the virtual showroom as well as showing all the house displays and products. The animation was looped until users selected another function.

3.2.2 Visit showroom. In this mode, users could control the camera's movements and were free to navigate around the showroom. Navigation was enabled by using arrow keys (controlling directions) and dragging the mouse with the scroll wheel button (controlling viewing angles). To depict realism, each of the "footsteps" was accompanied with sound when the arrow keys were pressed. The movement speed was designed in a moderate slow pace for users to spend longer time in their navigation.

3.2.3 Directory. The "directory" mode shows the layout of the virtual showroom from a bird's eye view (Figure 2). AEC displays are labeled with their respective brand logos and the name of the AEC range. These labels function as buttons, which allow users to enter the "customization" mode when clicked.

3.2.4 Customize. The "customize" button brought up four other buttons, showing the four AEC range displays. Choosing an AEC range button brought the users into the customization interface for that particular range. The customization interface is shown in Figure 3. There were two color palettes on the interface. The left palette represented color options for cabinet doors and drawers. The right palette showed the color options for the worktop. The color of the cabinet changed when users clicked on a color button and the same for the worktop. This function enables them to evaluate the effects of different combinations. For instance, they are able to conduct a visual appraisal of how well different styles and colors of cabinets and worktops work together.

3.2.5 Contact us. This button linked directly to a "contact" webpage which enabled consumers to get more information on contacting the manufacturer or supplier. Users can obtain more information on the selected products and appliances directly from the manufacturers' websites.

\subsection{Object behavior}

The interactivity feature of the real-time simulation was enabled by assigning object behaviors for individual virtual objects. This process enabled users to interact with the house displays, such as opening cabi- net doors, pulling drawers, and operating appliances. Consumers learned about functionalities of these components and fittings. Besides performing product functions, object behavior also provided product information. Objects assigned with specific behaviors were indicated by special cursors. In addition to using the cursor, animated objects serve the purpose of attracting recipients' attention, and directing them to perform a specific action.

Arrow-cued orienting was found to have an important effect on automatic shifts of attention (Hietanen et al., 2008). Advances in neuroimaging studies suggest that automatic orienting of visuospatial attention can be triggered by signaling, such as symbolic arrow cues (Hommel et al., 2001; Ristic et al., 2002). This line of work asserted that arrow cues are overlearned symbols and consequently provide relatively direct information regarding the to-be-attended location (Tipples, 2002).

When the cursor is rolled over an interactive object, such as the faucet in this example, it changes into icons with a specific meaning to inform users of the target actions on the objects. In Figure 4, the cursor illustrates the appropriate actions, such as clicking for obtaining product information, turning the water on/off, and rotating the faucet. The use of arrow cues would serve as the focal point to draw the users' attention to a specific location of the visual, as well as guide their interaction with a product.

The humanoid avatar was designed to depict real seller-buyer interaction by animating bodily movements and assigning speech. The avatar's speech was designed using text-to-speech software to transform written texts into verbal speech. The body animation was synchronized with the speech playing length each time the avatar performed the human action. The assigned object behavior and their functions are summarized in Table 2.

\subsection{Object behavior programming}

Each interactive object in the virtual showroom was assigned distinctive object behaviors. The object behavior is the result of an algorithm performed by a welldefined network of building blocks. The building block is the basic module that performs a specific behavior, such as "rotate", "wait message", "collision detection". The concept of object behavior programming is illustrated in Figure 5.

The interface for color and texture customization is illustrated in Figure 6. For this display, the left palette provides the available colors for the cabinet, and the right palette shows the textures for the worktops. Users can customize the color and texture, by clicking on the palette. The programming for color and texture customization is shown in Figure 7. 


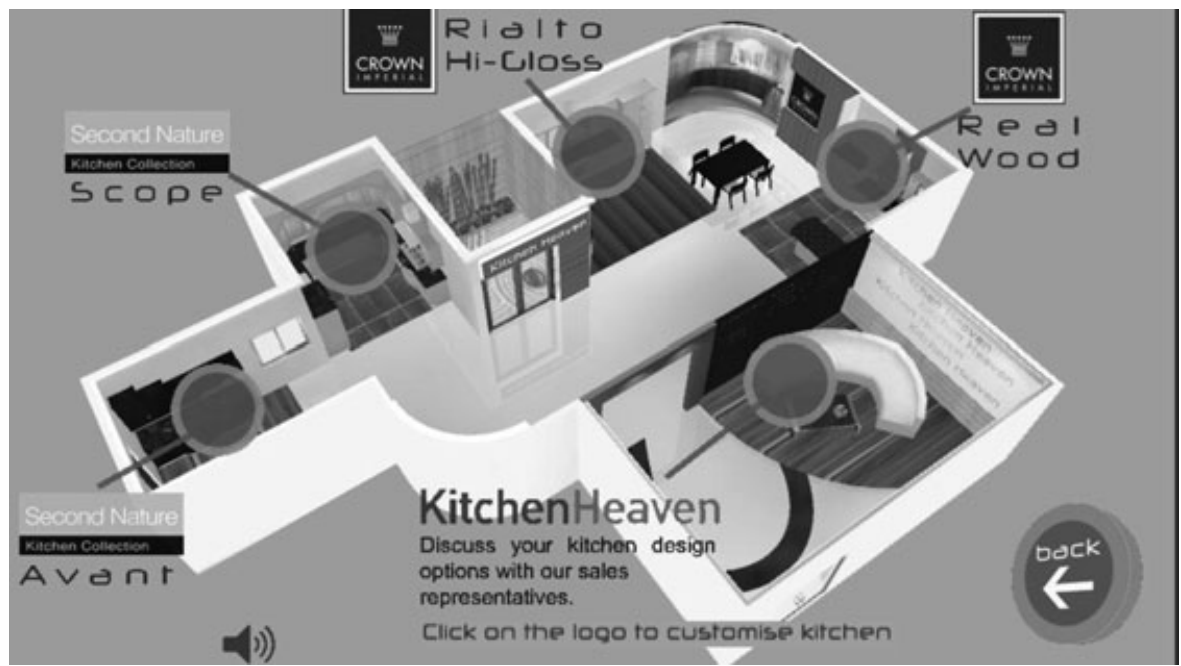

Fig. 2. Directory mode.

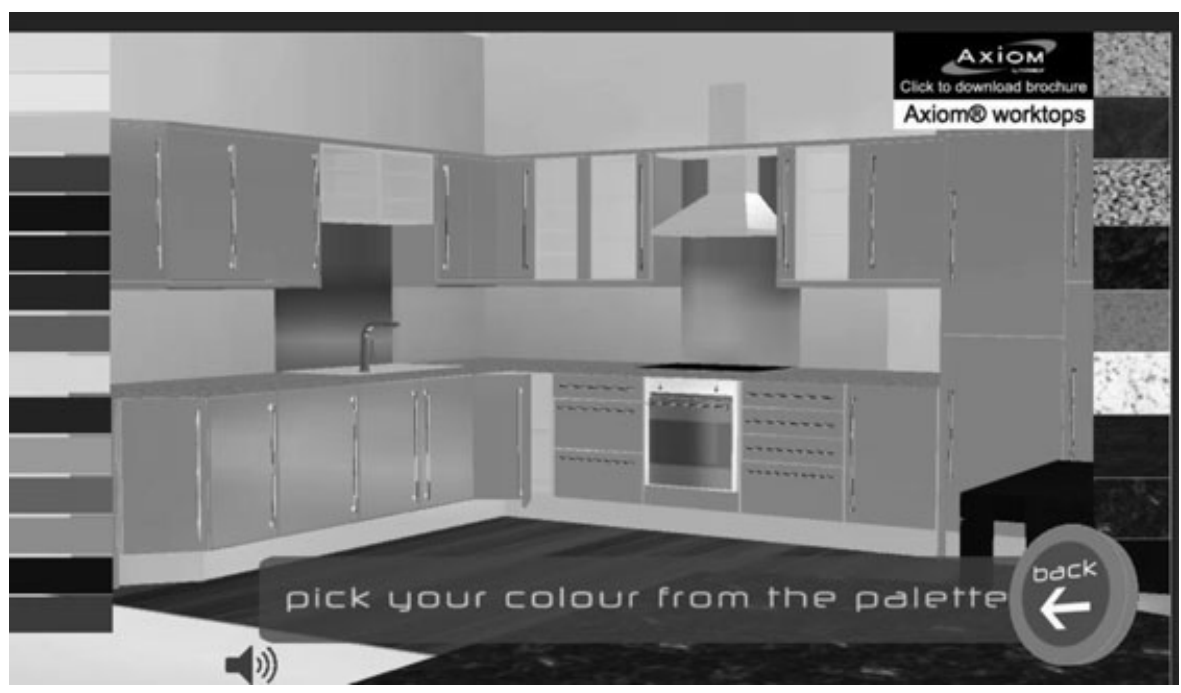

Fig. 3. Customization interface.

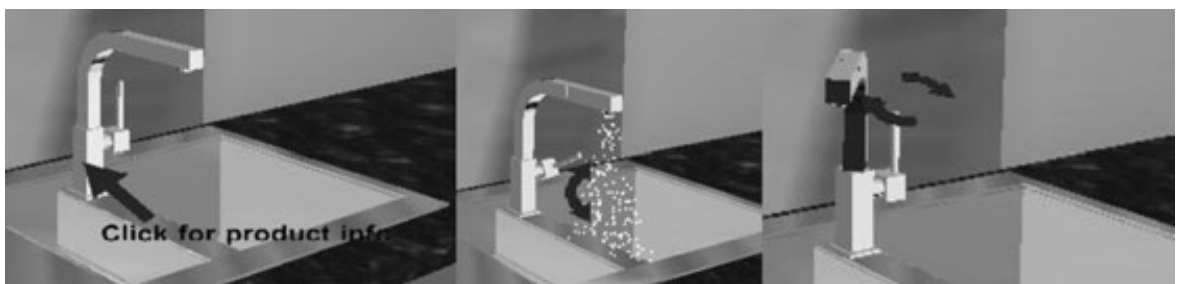

Fig. 4. Use of arrow cues to attract users' attention to trigger action on the product.

The functions of each building block are described as follows:

- the Wait Message building block awaits a specific "message" before proceeding with the next action;

- the Group Iterator building block defines a group that contains all the objects (which will change their texture once they receive a mouse click);
- the Set Material building block defines the texture to be used on a specified target object/group;

- the PushButton building block is activated when a defined button (from the color palette) is clicked and;

- the Show building block is activated to show the new texture on button press and the Hide building block will hide the old texture. 
Table 2

Virtual object behaviors

\begin{tabular}{|c|c|}
\hline Virtual objects & Object behavior functions \\
\hline $\begin{array}{l}\text { Computer } \\
\text { screens }\end{array}$ & $\begin{array}{l}\text { Opens new windows showing homepage } \\
\text { for the AEC and fittings manufacturers. }\end{array}$ \\
\hline 3D brochures & $\begin{array}{l}\text { Opens new windows of the respective } \\
\text { AEC and fittings manufacturers' website } \\
\text { for brochure download. }\end{array}$ \\
\hline Cabinet doors & $\begin{array}{l}\text { Opens or closes when left-mouse button is } \\
\text { clicked and dragged. }\end{array}$ \\
\hline Drawers & $\begin{array}{l}\text { Pulls out/in the drawers when left-mouse } \\
\text { button is clicked and dragged. }\end{array}$ \\
\hline Water taps & $\begin{array}{l}\text { Turn on/off water when left-mouse button } \\
\text { is clicked and dragged. }\end{array}$ \\
\hline Faucets & $\begin{array}{l}\text { Rotates the faucets when left-mouse } \\
\text { button is clicked and dragged. }\end{array}$ \\
\hline Oven doors & $\begin{array}{l}\text { Opens or closes when left-mouse button is } \\
\text { clicked and dragged. }\end{array}$ \\
\hline $\begin{array}{l}\text { AEC fittings } \\
\text { (taps, sinks, } \\
\text { and ovens) }\end{array}$ & $\begin{array}{l}\text { Opens new windows showing external } \\
\text { websites describing product information } \\
\text { and specifications. }\end{array}$ \\
\hline Rotating cube & $\begin{array}{l}\text { Opens the questionnaire webpage when } \\
\text { clicked. }\end{array}$ \\
\hline Avatar & $\begin{array}{l}\text { Creating users' social presence by } \\
\text { performing human actions through } \\
\text { bodily animation and verbal speech. }\end{array}$ \\
\hline
\end{tabular}

The humanoid avatar involved the programming of the character animation, voice playback, and camera view (Figure 8).

For the humanoid avatar, the functions of each building block are outlined below:

- the Switch On Message building block indicates the activation of the humanoid avatar's animation once the Next button is clicked;

- the Active Script building block activates the camera that shows the humanoid avatar;

- the Delayer building block delays the time before the voice playback;

- the Wave Player building block enables voice playback of the humanoid avatar and;
- the Play Global Animation building block enables the animation playback.

\subsection{Interface design for humanoid avatars}

The interface design and object behavior involved the inclusion of the humanoid avatar, Masha. Masha greets customers and gives a brief explanation of the user interface as shown in Figure 9. This scene depicts a reallife situation, where sales representatives greet visitors when they come to the showroom.

The additional submenu for this version is the "guided tour." Masha accompanies users on their visit to the VHS, and provides a presentation of their features. Users can proceed to the next display by clicking on the Next button. They can leave the guided tour at any time by clicking the Back button to move to the "visit showroom" mode. There is also a button showing Masha's face at the bottom of the screen to provide users with the option of asking for further help from her, when needed (Figure 9).

The real-time simulation is presented with other showroom visitors appearing in the form of animated silhouettes. This feature seeks to depict a real-life situation, where other visitors are present in the showroom, to improve the perception of social presence.

\subsection{The experiment design}

The experiment design is illustrated in Figure 10.

This research adopted the online survey method to obtain participants' responses to the VHS. Van Selm and Jankowski (2006) suggested the following rationale for conducting online surveys:

- reach a population with Internet experience;

- help in gaining access to respondents normally difficult to reach, as there is better anonymity on the Internet;

- facilitate the sharing of participants' experiences and opinions;

- offer convenience and speed in terms of data capture;

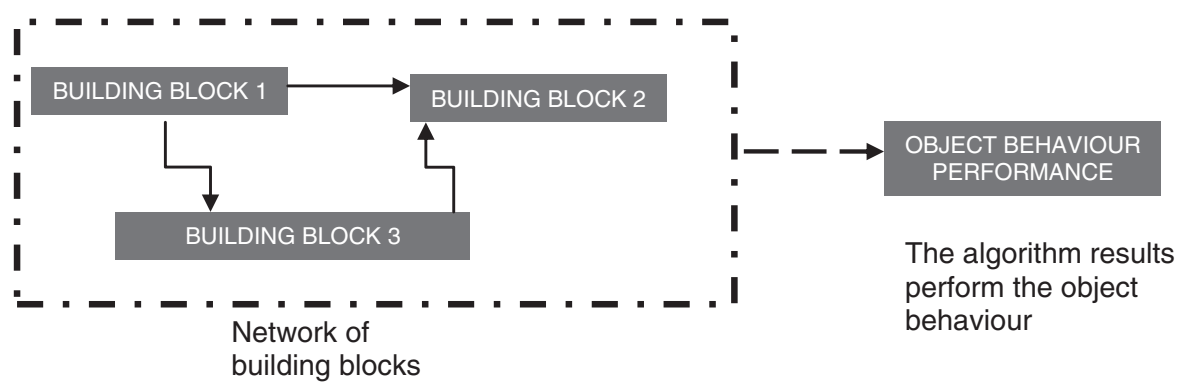

Fig. 5. Object behavior programming conceptualization. 


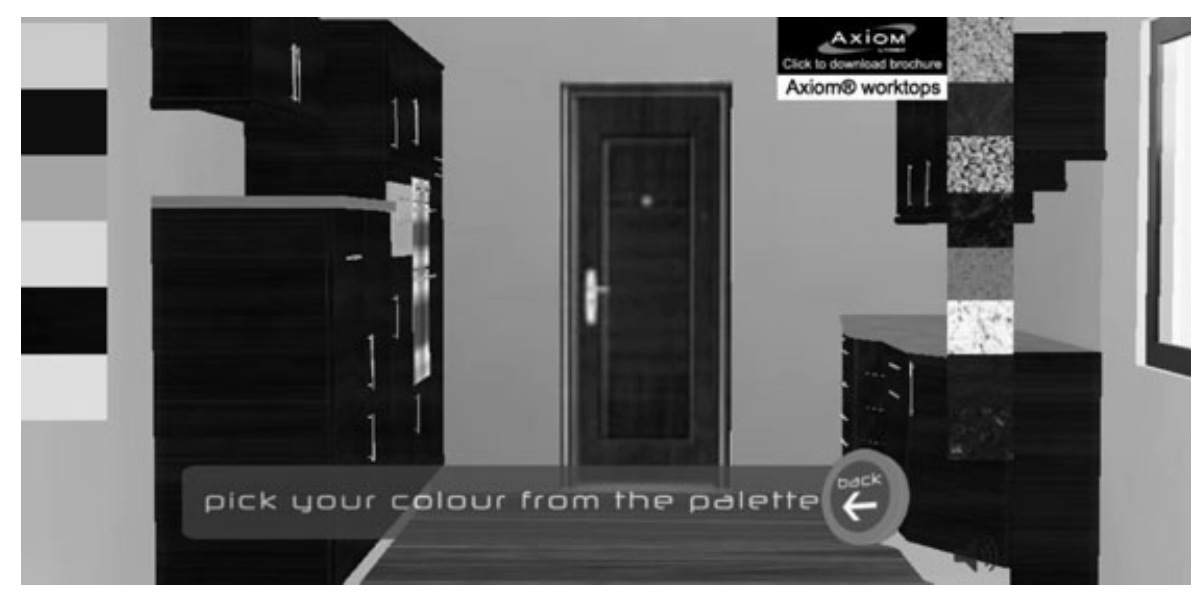

Fig. 6. House products color and texture customization.

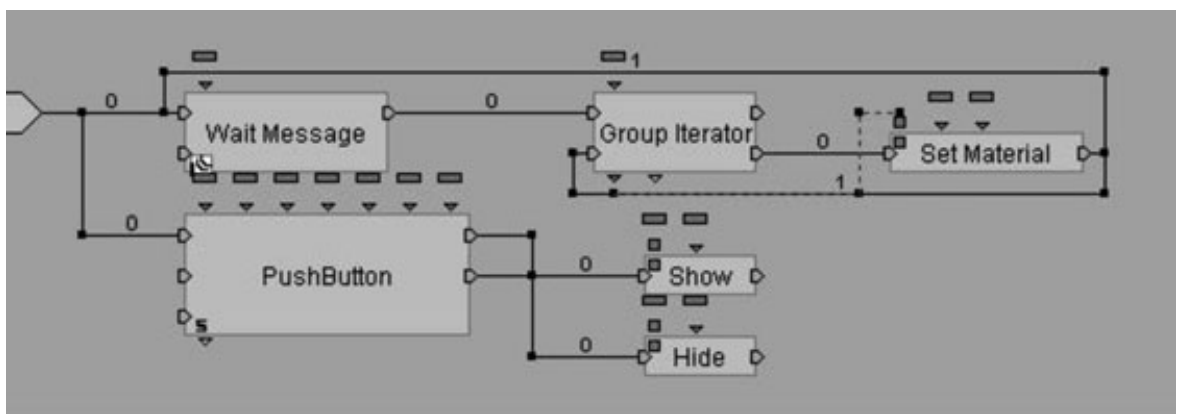

Fig. 7. Color and texture customization.

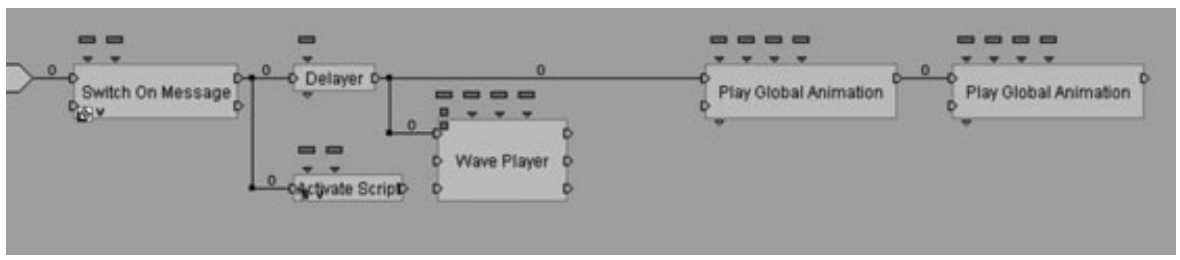

Fig. 8. Programming of the humanoid avatar.

- provide a cost effective option, compared to conventional survey methods and;

- reach a bigger population with lesser geographical constraints, increasing the possibility of recruiting respondents.

One hundred and ten participants participated in the research. The target audience of this research was consumers who spend time on Internet activities. Convenience sampling was used to recruit the respondents. Zhang (2000) argued that sampling bias might occur in online surveys, as individuals in a population who do not have access to the Internet may not be represented in the sample groups, while Van Selm and Jankowski (2006) stressed that online surveys are best suited for studies among non-probability samples.
Participants $(n=110)$ were organized into two groups. Personal characteristics of the respondents are shown in Table 3. Group $1(n=56)$ was involved in the evaluation of the VHS without the humanoid avatar (Study 1). Study 1 was designed to test the effects of the real-time simulation on consumers' cognitive learning, affect, and behavior. Group $2(n=$ 54) examined the same effects, with the presence of a humanoid avatar (Study 2). An online questionnaire using a 1-5 rating Likert scale was used for data collection (1 strongly agree and 5 strongly disagree). Participants' responses to the VHS (without and with the presence of the humanoid) were evaluated along several dimensions: cognitive learning, affective learning, and conation and purchasing behavior (Tables 4-6). 


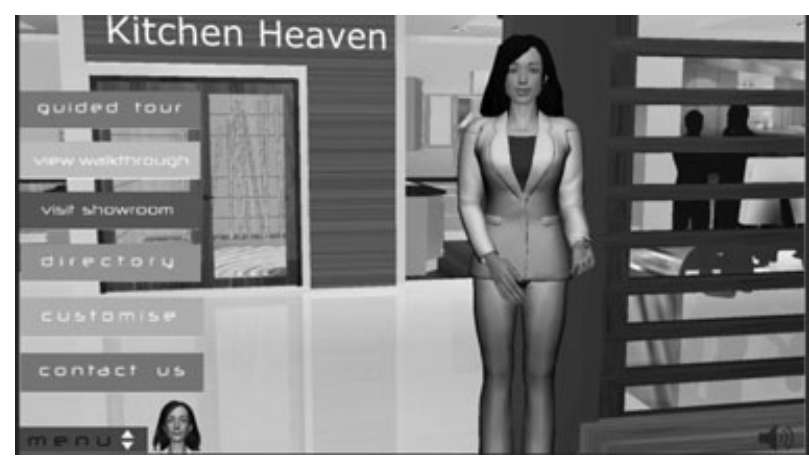

Fig. 9. Opening scene for humanoid avatar interface.

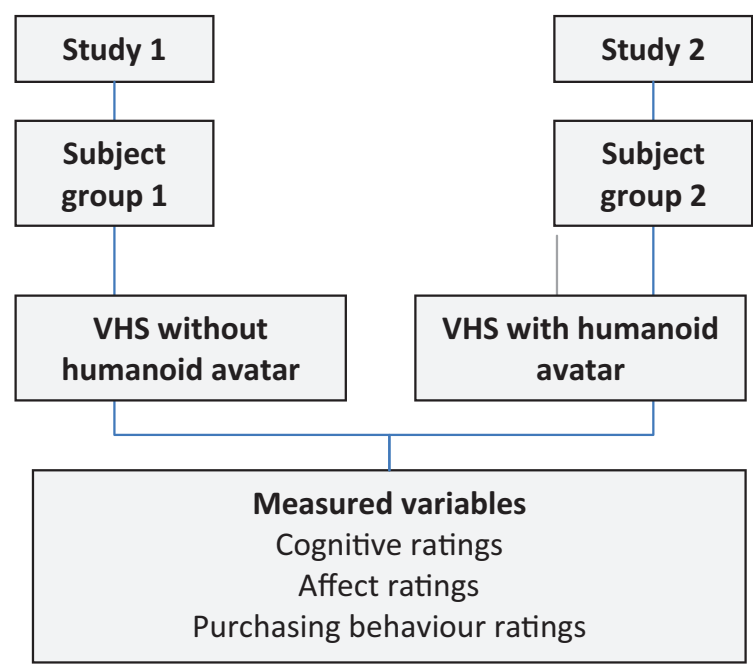

Fig. 10. Experiment design.

\subsection{Hypotheses}

Study 1 was used to test the following hypotheses:

$\mathrm{H}_{1}$ : It is predicted that real-time simulation will have a significant effect on consumers' cognitive learning about the AEC product features and functions.

$\mathrm{H}_{2}$ : It is expected that real-time simulation will have a significant effect on consumers' affect towards the AEC products.

$\mathrm{H}_{3}$ : It is likely that real-time simulation will have a significant effect on consumers' purchasing behavior.

A Chi-square test was used to compare the observed frequencies of rating scores, with the expected frequencies.

Study 2 was used to test the following hypothesis:

$\mathrm{H}_{4}$ : It is predicted that the humanoid avatar in the real-time simulation will have a significant effect on consumers' cognitive learning, affect, and behavior, compared to the VHS model without the humanoid avatar.

The Mann-Whitney test is one of the most commonly used tests to compare two groups with regard to a given
Table 3

Participants' characteristics

\begin{tabular}{llccr}
\hline & & \multicolumn{2}{c}{ Groups } & \\
\cline { 3 - 4 } & & Study 1 & Study 2 & Total \\
\hline Age group (years) & $<25$ & 18 & 16 & 34 \\
& $25-54$ & 36 & 35 & 71 \\
Total & $>54$ & 2 & 3 & 5 \\
Gender & & 56 & 54 & 110 \\
Total & Female & 24 & 21 & 45 \\
& Male & 32 & 33 & 65 \\
& & 56 & 54 & 110 \\
\hline
\end{tabular}

criterion that is measured on at least an ordinal scale (Pett, 1997). This test was deemed appropriate to compare differences between the two independent groups in Studies 1 and 2 to determine whether the presence of the humanoid avatar had a significant effect on their ratings.

\section{RESULTS OF USERS' EVALUATION OF THE VIRTUAL HOUSE SHOWROOM}

The following section presents the findings of participants' evaluation of the virtual showroom. This includes the effects of real-time simulation and humanoid avatars on consumers' cognitive and affective learning, as well as their conation and purchasing behavior.

\subsection{Effects of real-time simulation and avatar on consumers' cognitive learning}

Study 1 involved the examination of consumers' responses to the real-time showroom, without the humanoid avatar. Participants evaluated the real-time simulation without the avatar. The test hypothesis predicted that real-time simulation will have a significant effect on consumers' cognitive learning about house product features and functions. Seven product characteristics were used to test this hypothesis, as shown in Table 4. Participants' responses were entered into an online questionnaire, and analyzed using the SPSS software.

The results of the Chi-square test confirmed that realtime simulation, without the humanoid avatar, had a significant effect on consumers' cognitive learning about house product features.

Using the same evaluation criteria, test 2 examined the effects of the humanoid avatar on consumers' cognitive learning. Based on the results of the Mann-Whitney test, it is possible to infer that there is no significant association between real-time simulation, containing the humanoid avatar, and consumers' cognitive learning. 
Table 4

Effects of VHS with humanoid avatar on consumers' cognitive learning

\begin{tabular}{|c|c|c|c|c|c|c|c|c|}
\hline & Tests & $\begin{array}{l}\text { Understand } \\
\text { how } \\
\text { cabinet } \\
\text { doors and } \\
\text { drawers } \\
\text { work }\end{array}$ & $\begin{array}{c}\text { Appreciate } \\
\text { how house } \\
\text { appliances } \\
\text { and fittings } \\
\text { work }\end{array}$ & $\begin{array}{c}\text { Learn } \\
\text { about new } \\
\text { styles }\end{array}$ & $\begin{array}{l}\text { Ability to } \\
\text { customize } \\
\text { color of } \\
\text { cabinets } \\
\text { and doors }\end{array}$ & $\begin{array}{c}\text { Gain more } \\
\text { information } \\
\text { about } \\
\text { product } \\
\text { functionality }\end{array}$ & $\begin{array}{c}\text { Obtain } \\
\text { more } \\
\text { accurate } \\
\text { information } \\
\text { about } \\
\text { product } \\
\text { attributes }\end{array}$ & $\begin{array}{c}\text { Verbal } \\
\text { informations } \\
\text { provides } \\
\text { clear } \\
\text { description } \\
\text { about } \\
\text { products }\end{array}$ \\
\hline $\begin{array}{l}\text { without } \\
\text { avatars }\end{array}$ & Asymp. sig. & 0.000 & 0.000 & 0.004 & 0.000 & 0.000 & 0.000 & 0.000 \\
\hline $\begin{array}{l}\text { Real-time } \\
\text { simulation }\end{array}$ & $\begin{array}{l}\text { Mann- } \\
\text { Whitney U }\end{array}$ & $1,472.500$ & $1,307.000$ & $1,297.000$ & $1,471.500$ & $1,433.500$ & $1,449.000$ & $1,346.000$ \\
\hline with & $\mathrm{Z}$ & -0.257 & -1.403 & -1.347 & -0.258 & -0.501 & -0.394 & -1.053 \\
\hline
\end{tabular}

Table 5

Effects of real-time simulation and avatar on consumers' affective learning

\begin{tabular}{|c|c|c|c|c|c|c|c|}
\hline & Tests & $\begin{array}{c}\text { Experience } \\
\text { of the virtual } \\
\text { showroom }\end{array}$ & $\begin{array}{c}\text { Evaluation } \\
\text { of the color } \\
\text { scheme }\end{array}$ & $\begin{array}{c}\text { Appraisal of } \\
\text { the style of } \\
\text { furniture }\end{array}$ & $\begin{array}{c}\text { Judgement } \\
\text { of interior } \\
\text { design }\end{array}$ & $\begin{array}{c}\text { User- } \\
\text { friendliness } \\
\text { of the virtual } \\
\text { showroom }\end{array}$ & $\begin{array}{c}\text { Feeling of } \\
\text { engagement } \\
\text { during } \\
\text { interaction } \\
\text { with virtual } \\
\text { displays }\end{array}$ \\
\hline $\begin{array}{l}\text { Real-time } \\
\text { simulation } \\
\text { without } \\
\text { avatars }\end{array}$ & Chi square & 39.000 & 46.143 & 10.429 & 28.107 & 77.393 & 65.964 \\
\hline \multirow{3}{*}{$\begin{array}{l}\text { Real-time } \\
\text { simulation } \\
\text { with avatars }\end{array}$} & $\begin{array}{l}\text { Mann- } \\
\text { Whitney U }\end{array}$ & $1,339.000$ & $1,383.000$ & $1,292.500$ & $1,431.000$ & $1,389.000$ & $1,344.000$ \\
\hline & $\mathrm{Z}$ & -1.146 & -0.838 & -1.360 & -0.517 & -0.823 & -1.095 \\
\hline & Asymp. sig. & 0.252 & 0.402 & 0.174 & 0.605 & 0.410 & 0.274 \\
\hline
\end{tabular}

\subsection{Effects of real-time simulation and avatar on consumers' affective learning}

The test hypothesis 2 predicted that real-time simulation will have a significant effect on consumers' affective learning about house product features and functions. Using six house product features, the test produced the following results about consumers' affective learning.

Based on the results, there is evidence to suggest that real-time simulation had a significant effect on consumers' affective learning about house product features. However, real-time simulations with the humanoid avatar did not significantly affect consumers' affective learning.

\subsection{Effects of real-time simulation and avatar on consumers' conation and purchasing behavior}

Hypothesis 3 envisaged that real-time simulation will have a significant effect on consumers' conation and purchasing behavior. The results are presented in Table 6 using a six-point categorization of house product features.

The findings confirmed that there is a significant association between real-time simulation and consumers' purchasing behavior. However, real-time simulation, with the humanoid avatar, did not significantly affect consumers' behavior, compared to the version without the avatar. 
Table 6

Effects of real-time simulation and avatar on consumers' conation and purchasing behavior

\begin{tabular}{|c|c|c|c|c|c|c|c|}
\hline & Tests & $\begin{array}{l}\text { Intention to } \\
\text { use virtual } \\
\text { showroom to } \\
\text { look for } \\
\text { information } \\
\text { on house } \\
\text { products }\end{array}$ & $\begin{array}{c}\text { Plan to } \\
\text { contact } \\
\text { suppliers for } \\
\text { purchasing } \\
\text { house } \\
\text { products }\end{array}$ & $\begin{array}{l}\text { Capability of } \\
\text { the virtual } \\
\text { showroom to } \\
\text { select } \\
\text { appropriate } \\
\text { products }\end{array}$ & $\begin{array}{c}\text { Assistance } \\
\text { of the virtual } \\
\text { showroom to } \\
\text { make } \\
\text { appropriate } \\
\text { decisions }\end{array}$ & $\begin{array}{c}\text { Ability to } \\
\text { learn about } \\
\text { house } \\
\text { product } \\
\text { attributes } \\
\text { from virtual } \\
\text { showroom }\end{array}$ & $\begin{array}{c}\text { Recommend } \\
\text { the virtual } \\
\text { showroom to } \\
\text { others }\end{array}$ \\
\hline $\begin{array}{l}\text { Real-time } \\
\text { simulation } \\
\text { without } \\
\text { avatars }\end{array}$ & Asymp. sig. & 0.000 & 0.001 & 0.014 & 0.004 & 0.000 & 0.000 \\
\hline \multirow{2}{*}{$\begin{array}{l}\text { Real-time } \\
\text { simulation } \\
\text { with avatars }\end{array}$} & $\begin{array}{l}\text { Mann- } \\
\text { Whitney U }\end{array}$ & $1,473.000$ & $1,287.000$ & $1,316.500$ & $1,276.000$ & $1,394.500$ & $1,270.500$ \\
\hline & $Z$ & -0.247 & -1.416 & -1.216 & -1.465 & -0.743 & -1.545 \\
\hline
\end{tabular}

\section{DISCUSSION}

The results show that real-time simulation, without the humanoid avatar, had a significant effect on consumers' cognitive and affective learning, as well as their purchasing behavior. This finding supports the research evidence of previous studies that found that online interactive products provide more product information (Park et al., 2008), improve users' recall of information (Suh and Lee, 2005), and enhance their enjoyment and satisfaction (Lee and Chung, 2008). It also confirms Kroeber-Riel's contention that high-level stimulation activates consumers to a significant extent to perform effective product learning and evaluation (KroeberRiel, 1995).

This article addressed the importance of maintaining human contact in online AEC marketing. From the comparisons of consumers' evaluation of real-time simulations, with the humanoid avatar, Masha, it is possible to infer that avatars have no significant effects on consumers' responses. The avatars did not influence consumers' cognitive learning, affect, and purchasing behavior to a significant extent. These results suggest that the real-time simulation is sufficient to perform the intended marketing purposes without the need for humanoid avatars. These findings are not in agreement with the results of Holzwarth et al. (2006) on the effects of avatars on consumers' behavior. A possible reason for the discrepancy is that Holzwarth et al. (2006) compared users' responses towards the stimulus with $2 \mathrm{D}$ avatars and stimulus with only text descriptions. The experiment by Bauer and Neumann (2005) did not involve virtual product interactions, as they used travel insurance counseling for the scenario design. This unexpected finding may also be due to the limitation of the avatar, Masha, in the VHS to fully depict real-life purchasing experience, including social presence. Avatars could be useful to create social presence to stimulate the imagination of human interactions. Emerging evidence suggests that online consumer-to-consumer interactions contribute significantly to shoppers' perceptions of interactivity and their attitudes toward the online shopping experience (Cui et al., 2010). The silhouettes depicting other visitors in the VHS were purposefully designed to serve this purpose. However, the extent to which social presence of humanoid avatars can generate positive influence on consumers is affected by the Technology Acceptance Model (TAM), trust and enjoyment factors (Hassanein and Head, 2007). The specific effects of social presence of humanoid avatars on consumers' behavior were not fully addressed in this study, and therefore may have failed to provide a realistic consumer experience.

Although the avatar may not have a significant effect on consumers' product learning and evaluation, its presence may still enhance consumers' visiting experience. For example, avatars may help users immerse in the virtual environment easily due to similarity-attraction and consistency-attraction (Lee and Nass, 2003). Recent advances in artificial intelligence (AI) have paved the way for the development of the Intelligent Software Assistant (ISA) that can organize information, learn processes, adapt to changing situations, and interactively support individuals in their tasks (Gouin et al., 2012). A recent successful implementation of ISA is the Apple iPhone's Speech Interpretation and Recognition Interface (Siri) that confirms the importance of the virtual all-in-one personalized assistant for consumers. Siri is designed to direct consumers to the applications, services, and information they need by combining 
techniques from fields such as voice recognition and natural language processing to process queries in Apple's server. It has access to databases of information, coined as "active ontologies" that are specifically focused on helping users in particular domains (Aron, 2011). Although both Masha and Siri are designed to offer help on demand, the processing of users' requests by Siri is more sophisticated. The humanoid avatar in the VHS is pre-programmed to primarily respond to consumers' queries and support them in their purchasing decisions. In addition, Siri is voice-controlled and interacts with the user through textual or auditory cues. A major limitation of the voice recognition systems is that they sometimes do not process input data precisely, which results in less accurate output information (Darre and Yussupov, 2011). Masha offers consumers a multisensory experience, as they are able to see her stationary and moving through the VHS, listen to her comments and explanations, and interact with her through a mouse controlled device. Future research should strive to harness advances in artificial intelligence to generate smarter and more credible avatars. Likewise, it is critical to gain a better understanding of the effects of the presence of avatars as personal assistants, as well as consumers' social contacts (i.e., consumer-to-consumer interaction).

One of the key findings of this research is that interactivity in the online real-time simulation has a significant impact on consumers' responses, including product learning and evaluation. This result is in agreement with Belcher's (K.N. Belcher, University of Missouri-Columbia, unpublished results) conclusions that interactivity has a significant effect on consumers' product learning. It also supports Cui et al.'s (2010) findings that consumers' perceptions of the control, responsiveness, and synchronicity of the website have a strong influence on their attitude. These results confirm that AEC companies should be fully aware of the role of interactivity to improve clients' online marketing experience. They may need to focus on enhancing users' experience in their interaction with the virtual products. It is important to present the AEC products' functionality and appearance as close as possible to reality to improve consumers' engagement. In addition, avatars may be used as an additional medium to enhance consumers' visiting experience.

The VHS model, developed as part of this study, has demonstrated the potential of novel approaches in interactive real-time simulation to allow AEC companies and organizations to successfully adopt e-marketing and exploit its full potential. As online shopping has become consumers' lifestyle, web-based VR has the potential to bring new virtual experiences in AEC marketing to consumers. Online VR may be integrated with the consumers' decision-making stages in product purchasing, as proposed by Oh et al. (2004). Further research is needed to identify at which stage of the buying experience web-based VR is more effective in informing and persuading consumers in online AEC marketing.

\section{CONCLUSION}

High level interactive presentation techniques have offered house product manufacturers and sellers more powerful features to present product functions and variations. This research proposed a novel computational approach for engaging consumers and supporting their decision-making process about purchasing house products. It developed and tested an online interactive real-time simulation for house product marketing (the Virtual House Showroom-VHS). VHS was presented to a sample of consumers with and without humanoid avatars, representing a virtual buyer-seller experience. The aim was to determine whether the presence or the absence of the humanoid avatar affected consumers' responses to the Virtual Showroom.

The findings of this study confirmed that consumers responded positively towards the real-time simulation. Subjects' personal characteristics (age groups and gender) had no significant effects on their responses towards the real-time simulation. The results established that real-time simulation has significant effects on subjects' cognitive learning about house products, and their affect towards the house products. In addition, the VHS had significant effects on participants' purchasing behavior. However, contrary to expectation, the findings revealed that the presence of the humanoid avatar in the real-time simulation had no significant effect on subjects' cognitive learning, affect, and purchasing behavior. This may be attributed to the absence of successful social presence stimulation factors, such as the Technology Acceptance Model, trust and enjoyment factors in the VHS. Further research is needed to address these limitations.

The research findings have several implications on online AEC marketing. Firstly, the positive evaluation by respondents confirms the potential of using real-time simulation, as an effective AEC marketing medium. The simulation provided a new way of product learning that could not be achieved by conventional media. It also established that consumers' virtual experience in AEC shopping could be enhanced by using online realtime simulation to present AEC products in an interactive and engaging way. Further work is needed to generalize these findings to other types of AEC domains and products. 


\section{REFERENCES}

Adeli, H. \& Kim, H. (2000), Web-based interactive courseware for steel design using Java, Computer-Aided Civil and Infrastructure Engineering, 15(2), 158-66.

Amica (2008), Welcome to the partner service of Amica Wronki S.A. [Homepage of Amica]. Available at: https://partner.amica.com.pl/produkty/virtools/?switch lang=en, accessed August 17, 2011.

Anumba, C. J. \& Ruikar, K. (2002), E-commerce in construction: trends and prospects, Automation in Construction, 11, 265-75.

Aron, J. (2011), How innovative is Apple's new voice assistant, Siri? New Scientist, 2836. Available at: http://www. newscientist.com/article/mg21228365.300-how-innovativeis-apples-new-voice-assistant-siri.html, accessed April 20, 2012.

Bauer, H. H. \& Neumann, M. M. (2005), Investigating the effects of avatars as virtual representatives in electronic commerce, ANZMAC 2005 Conference: Electronic Marketing.

Bezjian-Avery, A., Calder, B. \& Iacobucci, D. (1998), New media interactive advertising vs. traditional advertising, Journal of Advertising Research, 38(4), 23-32.

British Broadcasting Corporation (2007), Online retailing 'surging ahead'. Available at: http://news.bbc.co.uk/ 1/low/business/6690397.stm, accessed March 20, 2011.

Chartered Institute of Marketing (2008), Marketing glossary [Homepage of The Chartered Institute of Marketing]. Available at: http://www.cim.co.uk/KnowledgeHub/ MarketingGlossary/GlossaryHome.aspx, accessed September 3, 2008.

Cui, N., Wang, T. \& Xu, S. (2010), The influence of social presence on consumers' perceptions of the interactivity of Web Sites, Journal of Interactive Advertising, 11(1), 36-49.

Darre, V. \& Yussupov, R. (2011), SIRI technology exploration and implementation in healthcare, in Proceedings of the Eleventh Annual Freshman Conference, University of Pittsburgh, April 9, 2011, 2182-86.

Dassault Systems (2007), 3D unveils the mystery of the great pyramid [Homepage of Dassault Systèmes]. Available at: http://khufu.3ds.com/introduction/, accessed January 23, 2011.

Dauner, J., Landauer, J., Stimpfig, E. \& Reuter, D. (1998), 3D product presentation online: the virtual design exhibition, VRML '98, in Proceedings of the Third Symposium on Virtual Reality Modeling Language, February 16-20, 1998, ACM, 57-62.

Dossick, C. S., Mukherjee, A., Rojas, E. M. \& Tebo, C. (2010), Developing construction management events in situational simulations, Computer-Aided Civil and Infrastructure Engineering, 25, 205-17.

Fishbein, M. \& Ajzen, I. (1975), Belief, Attitude, Intention and Behaviour: An Introduction to Theory and Research. Addison Wesley, Reading, MA.

Foxall, G. \& Goldsmith, R. (1998), Consumer Psychology for Marketing, 2nd edn. International Thomson Business, London.

Fu, M. C. \& East, E. W. (1999), The virtual design review, Computer-Aided Civil and Infrastructure Engineering, 14, 25-35.

Garau, M., Slater, M., Bee, S. \& Sasse, M. A. (2001), The impact of eye gaze on communication using humanoid avatars, in Proceedings of the Human Factors in Computing Systems, CHI 01, ACM Press, 309-16.
Garrison, D. R. \& Anderson, T. (2003), E-Learning in the 21st Century: A Framework for Research and Practice. Routledge, New York.

Gouin, D., Lavigne, V. \& Bergeron-Guyard, A. (2012), Human-computer interaction with an intelligence virtual analyst, in Proceedings of Knowledge Systems for Coalition Operations, IHMC, Pensacola, FL, February 15-17, 2012.

Hassanein K. \& Head, M. (2007), Manipulating perceived social presence through the web interface and its impact on attitude towards online shopping, International Journal of Human-Computer Studies, 65(8), 689-708.

Hemp, P. (2006), Avatar-based marketing, Harvard Business Review, 84(6), 48-51.

Hietanen, J. K., Leppänen, J. M., Nummenmaa, L. \& Astikainen, P. (2008) Visuospatial attention shifts by gaze and arrow cues: an ERP study, Brain Research, 1215, 12336.

Holzwarth, M., Janiszewski, C. \& Neumann, M. M. (2006), The influence of avatars on online consumer shopping behaviour, Journal of Marketing, 70(4), 19-36.

Hommel, B., Pratt, J., Colzato, L. \& Godijn, R. (2001), Symbolic control of visual attention, Psychological Science, 12, 360-65.

Kaplan, A. M. \& Haenlein, M. (2009), Consumer use and business potential of virtual worlds: the case of "Second Life", International Journal on Media Management, 11(3-4), 93-101.

Kiang, M.Y., Raghu, T.S. \& Shang, K.H. (2000), Marketing on the internet-who can benefit from an online marketing approach, Decision Support Systems, 27(4), 383-93.

Kohler, T., Matzler, K. \& Füller, J. (2009), Avatar-based innovation: using virtual worlds for real-world innovation, Technovation, 29, 395-407.

Kroeber-Riel, W. (1995), Konsumentenverhalten, 5th edn. Vahlen, München, Germany.

Kuldeep, K. S., George, K. K. \& Roberto, C. (2012), Consistent point clouds of narrow spaces using multiscan domain mapping, Computer-Aided Civil and Infrastructure Engineering, 27(4), 1-18.

Lavidge, R. J. \& Steiner, G. A. (1961), A model for predictive measurements of advertising effectiveness, Journal of Marketing, 25(6), 59-62.

Lee, K. C. \& Chung, N. (2008), Empirical analysis of consumer reaction to the virtual reality shopping mall, Computers in Human Behavior, 24(1), 88-104.

Lee, K. M. \& Nass, C. (2003), Designing social presence of social actors in human-computer interaction, in Proceedings, SIGCHI Conference on Human Factors in Computing Systems, Florida, April 5-10, 5(1), 289-96.

Mcmillan, S. J. \& Hwang, J. S. (2002), Measures of perceived interactivity: an exploration of the role of direction of communication, user control, and time in shaping perceptions of interactivity, Journal of Advertising, 31(3), $29-42$.

Mowen, J. C. \& Minor, M. (1997), Consumer Behavior, Prentice-Hall, Upper Saddle River, NJ.

Oh, H., Yoon, S. \& Hawley, J. (2004), What virtual reality can offer to the furniture industry, Journal of Textile and Apparel, Technology and Management, 4(1), 1-17.

Park, J., Stoel, L. \& Lennon, S. J. (2008), Cognitive, affective and conative responses to visual simulation: the effects of rotation in online product presentation, Journal of Consumer Behaviour, 7, 72-87. 
Peter, J. P. \& Olson, J. C. (2005), Consumer Behaviour and Marketing Strategy, 7th edn. McGraw-Hill, New York, London.

Pett, M. A. (1997), Nonparametric Statistics for Health Care Research. Sage Publications, London.

Qiu, L. \& Benbasat, I. (2005), Online consumer trust and live help interfaces: the effects of text-to-speech voice and three-dimensional avatars, International Journal of HumanComputer Interaction, 19(1), 75-94.

Ray, M. L. (1973), Marketing communication and the hierarchy of effects, in P. Clarke (ed.), New Models for Mass Communication Research, Sage Publications, Beverly Hills, 146-75.

Ristic, J., Friesen, C. K. \& Kingstone, A. (2002), Are eyes special? It depends on how you look at it, Psychonomic Bulletin and Review, 9, 507-13.

Stewart, D. W. \& Pavlou, P. A. (2002), From consumer response to active consumer: measuring the effectiveness of interactive media, Journal of the Academy of Marketing Science, 30(4), 376-96.

Suh, K. \& Lee, Y. E. (2005), Effects of virtual reality on consumer learning: an empirical investigation, MIS Quarterly, 29(4), 673-97.
Tipples, J, (2002), Eye gaze is not unique: automatic orienting in response to uninformative arrows, Psychonomic Bulletin \& Review, 9, 314-18.

Van Selm, M. \& Jankowski, N. W. (2006), Conducting online surveys, Quality and Quantity, 40(3), 43556.

Yee, N., Bailenson, J. N., Urbanek, M., Chang, F. \& Merget, D. (2007), The unbearable likeness of being digital: the persistence of nonverbal social norms in online virtual environments, Cyber Psychology and Behavior, 10(1), 115-21.

Zalama, E., Gómez-García-Bermejo, J., Llamas, J. \& Medina, R. (2011), An effective texture mapping approach for 3D models obtained from laser scanner data to building documentation, Computer-Aided Civil and Infrastructure Engineering, 26, 381-92.

Zaleon, P. (2007), Marketing savvy [Homepage of $\mathrm{Z}$ promotion \& design]. Available at: http://www. kitchenmarketing.com/kbdn-1107.htm, accessed July 12, 2011.

Zhang, Y. (2000), Using the Internet for survey research: a case study, Journal of the American Society for Information Science, 51(1), 57-68. 